\title{
INDEX OF SUBJECTS.
}

Air, bacteriological examination of in House of Commons $\ldots \quad \begin{array}{llll}\text { PAGE } \\ \end{array}$

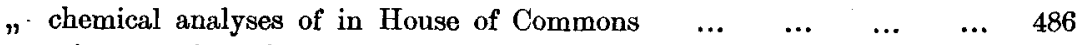

$"$ microorganisms in, influence of season, weather, altitude, locality, etc.

upon their numbers $\ldots \quad \ldots \quad \ldots \quad \ldots \quad 501$ et seq.

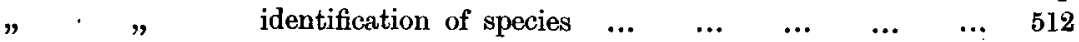

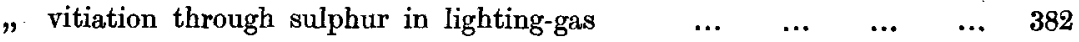

" see Caisson illness

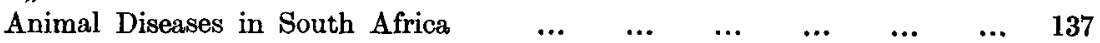

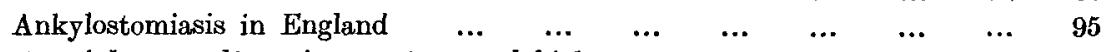

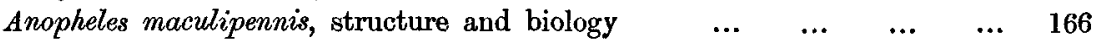

Antiseptics, intravascular use of $\quad \begin{array}{llllllllll} & \ldots & \ldots & \ldots & \ldots & \ldots & \ldots & 159\end{array}$

Antisera, see Precipitin

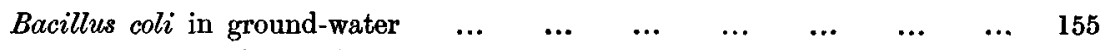

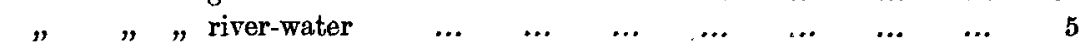

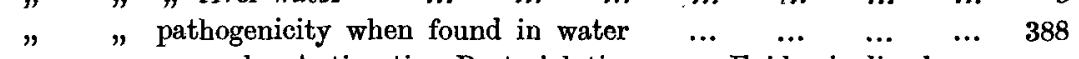

" " see under Antiseptics, Bacteriolytic serum, Epidemic diarrhoea

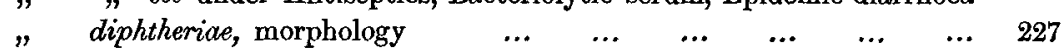

$\begin{array}{ccccccccc}" & \text { aiphtheriae, morphology } & \ldots & \ldots & \ldots & \ldots & \ldots & \ldots & 227 \\ " & n & \text { mode of dissemination } & \ldots & \ldots & \ldots & \ldots & \ldots & 238\end{array}$

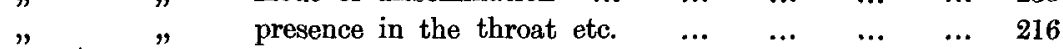

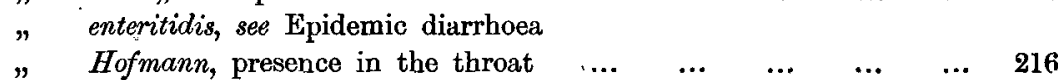

" pyocyaneus, see Antiseptics

" tuberculosis, see Tuberculosis

" typhosus, see Antiseptics, Bacteriolytic serum

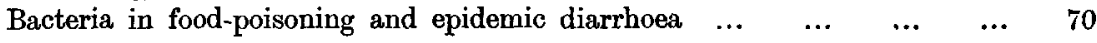

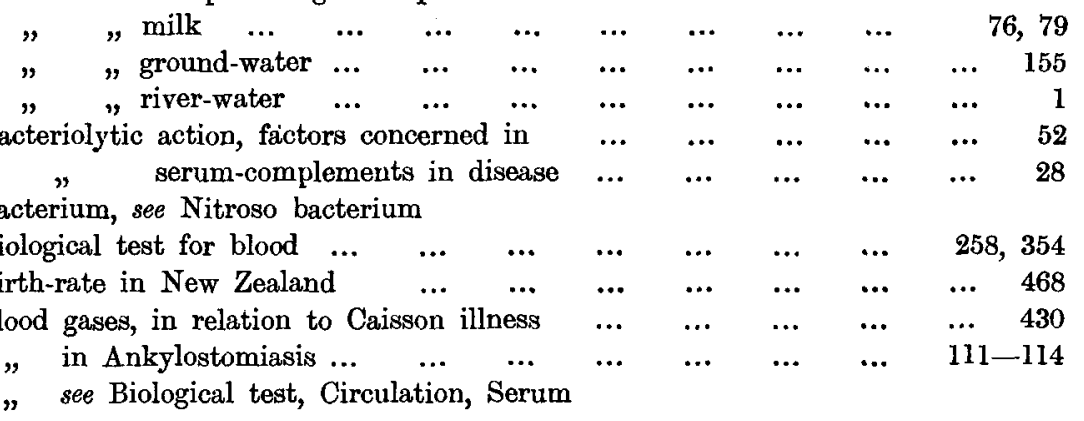


PAGE

$\begin{array}{llllllllll}\text { Books received } & \ldots & \ldots & \ldots & \ldots & \ldots & \ldots & \ldots & \ldots & 400,523\end{array}$

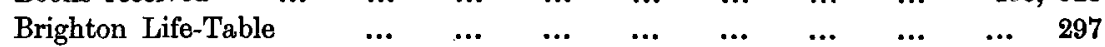

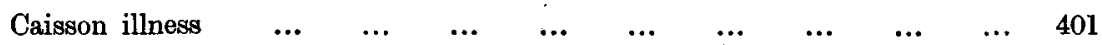

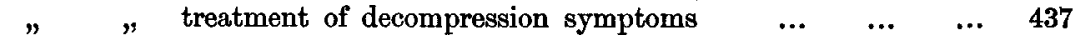

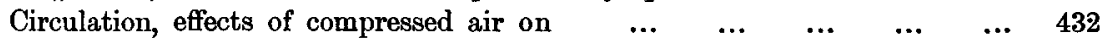

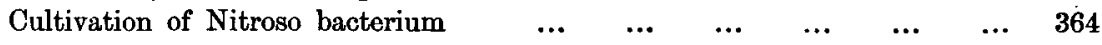

$\begin{array}{lllllllll}\text { Death-rate in New Zealand } & \ldots & \ldots & \ldots & \ldots & \ldots & \ldots & \ldots & 468\end{array}$

$\begin{array}{llllllllll}\text { Diarrhoea, infantile } \quad \ldots & \ldots & \ldots & \ldots & \ldots & \ldots & \ldots & \ldots & 468 \\ & \ldots & \ldots & \ldots & \ldots & \ldots & \ldots & \ldots & \ldots & 325\end{array}$

$\begin{array}{llllllllllll}\text { Diphtheria } & \ldots & \ldots & \ldots & \ldots & \ldots & \ldots & \ldots & \ldots & \ldots & \ldots & 216\end{array}$

$\begin{array}{lllllllllll}\text { Diver's palsy } & \ldots & \ldots & \ldots & \ldots & \ldots & \ldots & \ldots & \ldots & \ldots & \\ & & & & & & & & & & 401\end{array}$

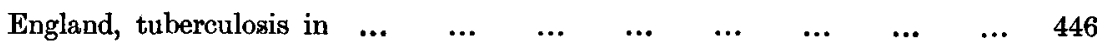

$\begin{array}{llllllllll} & \text { and Wules Life-table } & \ldots & \ldots & \ldots & \ldots & \ldots & \ldots & \ldots & 347\end{array}$

$\begin{array}{llllllllll}\text { Epidemic diarrhoea } & \ldots & \ldots & \ldots & \ldots & \ldots & \ldots & \ldots & \ldots & 68\end{array}$

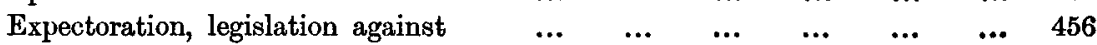

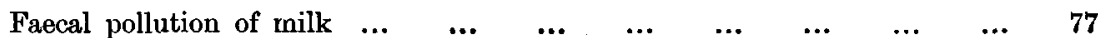

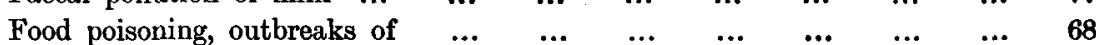

$\begin{array}{llllllll} & \text { price of, in relation to tuberculosis } & \ldots & \ldots & \ldots & \ldots & \ldots & 450\end{array}$

Graphic method, see Life-table

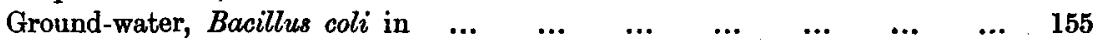

$\begin{array}{lllllllllll}\text { Heartwater } & \ldots & \ldots & \ldots & \ldots & \ldots & \ldots & \ldots & \ldots & \ldots & 147,149\end{array}$

$\begin{array}{llllllllll}\text { Horse-sickness } & \ldots & \ldots & \ldots & \ldots & \ldots & \ldots & \ldots & \ldots & 140,153\end{array}$

Immunity, see Bacteriolytic, Precipitin

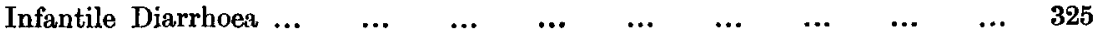

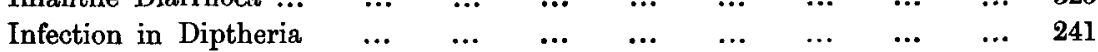

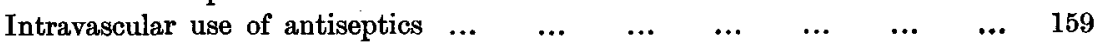

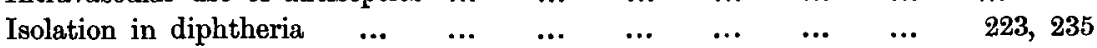

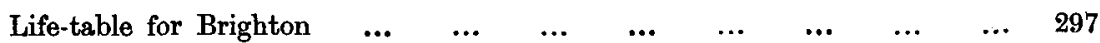

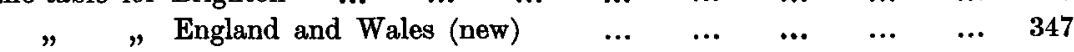

Lighting-gas, see Air

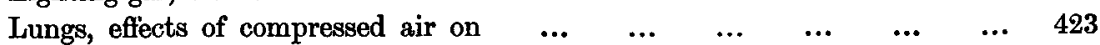

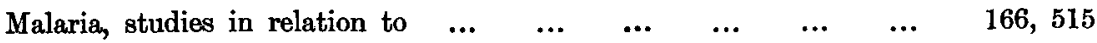

$\begin{array}{llllllll}\text { Medico-legal test for blood } & \ldots & \ldots & \ldots & \ldots & \ldots & \ldots & 258,354\end{array}$

$\begin{array}{lllllllll}\text { Milk and epidemic diarrhoea } & \ldots & \ldots & \ldots & \ldots & \ldots & \ldots & \ldots & 74\end{array}$

Mines, see Ankylostomiasis 
PAGE

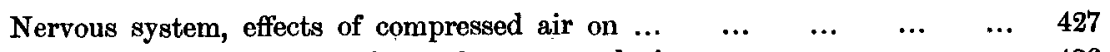

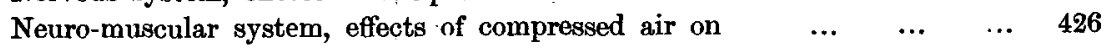

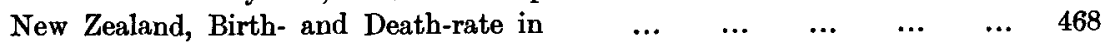

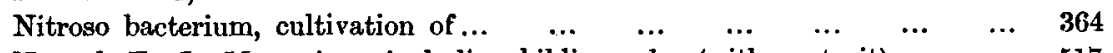

Nocard, E., In Memoriam, including bibliography (with portrait) ... $\quad \ldots \quad 517$

Outbreaks, see Epidemic, Ankylostomiasis

$\begin{array}{lllllllllllll}\text { Oxygen, toxic effects of } & \ldots & \ldots & \ldots & \ldots & \ldots & \ldots & \ldots & \ldots & 429\end{array}$

Phthisis, see Tuberculosis

$\begin{array}{llllllllllll}\text { Pipette for diluting serum, etc. } & \ldots & \ldots & \ldots & \ldots & \ldots & \ldots & & \ldots & 380\end{array}$

$\begin{array}{llllllllll}\text { Precipitin test for blood } \ldots & \ldots & \ldots & \ldots & \ldots & \ldots & \ldots & 258,354\end{array}$

Public Health Authorities and tuberculosis in England $\quad \ldots \quad \ldots \quad \ldots \quad \ldots \quad 446$

Pyocyaneus infection in rabbits, see Antiseptics

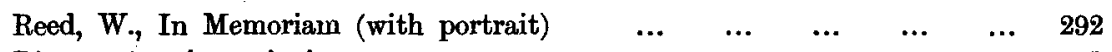

$\begin{array}{lllllllllll}\text { River-water, bacteria in } & \ldots & \ldots & \ldots & \ldots & \ldots & \ldots & \ldots & \ldots & 1\end{array}$

Sanatoria, see Tuberculosis

Serum-complements, see Bacteriolytic

Serum, pipette for diluting $\quad \begin{array}{lllllllllll} & \ldots & \ldots & \ldots & \ldots & \ldots & \ldots & \ldots & 380\end{array}$

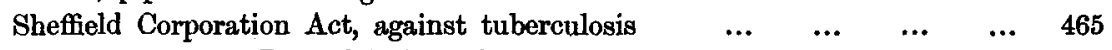

Streptococcus, see Bacteriolytic action

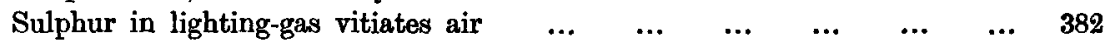

Test for blood, see Precipitin

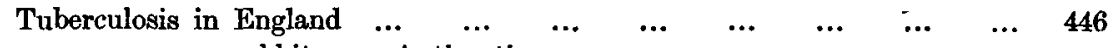

" " rabbits, see Antiseptics

$\begin{array}{lllllllllll}\text { Veld-Sickness } & \ldots & \ldots & \ldots & \ldots & \ldots & \ldots & \ldots & \ldots & 140,149\end{array}$

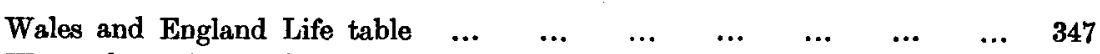

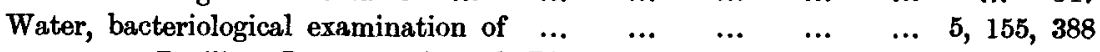

" see Bacillus, Bacteria, Ground, River

Yellow Fever, see Reed

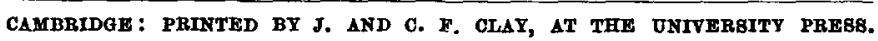

